\title{
Renewable Energy - Panacea for Climate Change?
}

\author{
Ö. Göl \\ School of Electrical and Information Engineering \\ University of South Australia \\ GPO Box 2471, Adelaide SA 5001, Australia \\ phone:+61 88302 3285, fax:+61 88302 3384, e-mail: Ozdemir.Gol@unisa.edu.au
}

\begin{abstract}
Within a few short decades, climate change has become a menacing reality rather than a remote possibility, threatening the planet Earth and its inhabitants. There is frantic activity at many fronts to thwart its advance and reverse the trend.

Use of renewable energy sources is often hailed as one of the measures in combating climate change. There are action plans based on international protocols, governments setting up mandatory renewable energy targets.

The paper gives an overview of climate change, critically examines the role of renewable energy as an encountering measure and solicits consolidated action with major emphasis on awareness raising and education.
\end{abstract}

\section{Key words}

Climate change, energy education, global warming, renewable energy, international protocols, energy legislation.

\section{Introduction}

There is a growing chorus of concerned voices which keep repeating with chilling consistency that we are running out of time in dealing with the greatest threat to Mother Earth and her inhabitants. Disturbing scenarios, painted with frightening detail, ring in our ears, are presented across our television screens, give rise to passionate debate at all levels. We are presented with fearful consequences such as losing land to rising sea levels, shortages of water due to the drying up of waterways and wetlands, sustained and increasingly more severe draughts, and deterioration of flora and fauna. Enough reasons for hearts to be gripped by fear!

But, could all this not be an exaggeration? After all, there have been other doomsayers throughout the history, even in more recent times. Were not millions going to perish due to famine in the 1970s according to the authors of the book Famine 1975, published in 1967? [1]. The apocalyptic predictions of that book were embraced and aggrandised in the bestseller, The Population Bomb, published the following year. The spinechilling words with which the topic was introduced were: "The battle to feed all of humanity is over. In the 1970's the world will un- dergo famines--hundreds of millions of people are going to starve to death in spite of any crash programs embarked upon now.” [2].

Forty years have passed since when those calamitous predictions were made. Mercifully, they have not come true! To the contrary: the rate at which food is produced has far exceeded the population growth, discrediting the projections [3]. So, could it be that the predictions regarding global warming and its projected dire consequences may also be blown over in the long run?

\section{Global Warming}

Global warming has been inextricably linked with the exploitation of fossil fuels. There are several issues beckoning attention in this context. Firstly, fossil fuels do not represent an endless source of supply of energy. Secondly, their continued use, even if they were inexhausti$b l e$, is the main source of generating green house gas emissions: now established as the main cause of global warming [4].

Problems have been compounding during the last two centuries or so - since the industrial revolution - without much cognisance by human societies. The utopian thinking by and large was that resources were endless and the sinks where we dumped our excesses were bottomless! So, crisis has crept up on us; despite the fact that the international community saw the need for the United Nations Conference on Human Environment, held at Stockholm, Sweden in 1972, which declared - inter alia “...We see around us growing evidence of man-made harm in many regions of the earth: dangerous levels of pollution in water, air, earth and living beings; major and undesirable disturbances to the ecological balance of the biosphere; destruction and depletion of irreplaceable resources; and gross deficiencies, harmful to the physical, mental and social health of man, in the man-made environment, particularly in the living and working environment.” [5]. This first such conference ever recommended "... that the General Assembly of the United Nations decide to convene a second United Nations Conference on the Human Environment; ..." so as to maintain the momentum of the first conference [6]. 
Yet, it took 20 long years before this second conference was finally convened: The Éarth Summit at Rio de Janeiro, Brazil, in 1992, "unprecedented for a UN conference, in terms of both its size and the scope of its concerns." [7]. This was followed - 10 years later - by The Earth Summit at Johannesburg which was dubbed Rio +10 . The so-called Johannesburg Declaration on Sustainable Development, recognised - among other things - that the future belongs to children "... who represent our collective future" and that we - accordingly have “...a collective responsibility to advance and strengthen the interdependent and mutually reinforcing pillars of sustainable development - economic development, social development and environmental protection at the local, national, regional and global levels.” [8].

\section{Climate Change}

Meanwhile, climate change has been advancing unabated, with Australia having its hottest year in 2005 ever since records started to be kept in 1910. The annual average temperature in 2005 was $1.09^{\circ} \mathrm{C}$ higher then period average between 1961 and 1969, seen as further verification that our climate is changing [9].

Yet, it has been relatively easy, especially for those deeply immersed in business or politics, to dismiss the warning signs of an impending global crisis. The position taken has been that utterances by scientists were unfounded myths and they were negative forces impeding the growth of economy. It was not until way past the middle of the last century that concerns were raised concerning the detrimental effects of unbridled exploitation on the collective riches of the planet and its inhabitants.

Global warming due to the excessive release of the socalled green house gas emissions in the process of generating heat to facilitate the energy conversion processes is now seen as the root cause of the climate change problems [4].

Climate change is no longer just a horror scenario dreamt up by a few eccentric scientists as it was thought to be just until very recently. It is real! So real that most credible warnings are sounded, alarming that dire consequences are in sight if no action is taken to combat this most real threat to the planet Earth. The awarding of the 2007 Nobel Peace Prize in December 2007 to the Intergovernmental Panel on Climate Change (IPCC) of the United Nations Organisation jointly with Al Gore has lent indisputable credibility to the claims that the planet Earth is in dire straits [10].

The problem of climate change is universal, not confined to a geographical region. It is overwhelming. The humankind is grappling with the problem, National dictates, priorities, even greed take their toll in the process toward achieving amicable and sustainable outcomes for all of Earth dwellers. The quest is to find out why all this is happening and how it can be stemmed. Solutions can not be expected without understanding cause-effect relationships.
It is now well established beyond reasonable doubt that climate change is the worst menace that the planet Earth has ever faced [4], [11], [12].

\section{Counter Measures}

Worldwide, counter measures are being put in place at a frantic pace. Kyoto Protocol [13] arguably represents the most decisive of these measures with its binding commitments to reduction in emissions and renewable energy targets. It legally binds the parties to the Protocol to “...individually or jointly, ensure that their aggregate anthropogenic carbon dioxide equivalent emissions of the greenhouse gases ... do not exceed their assigned amounts, calculated pursuant to their quantified emission limitation and reduction commitments ... with a view to reducing their overall emissions of such gases by at least 5 per cent below 1990 levels in the commitment period 2008 to 2012." [13]. Table 1 summarises the member states' commitments to reduction targets.

TABLE I. - Greenhouse gas emission targets for 2008-2012 (Kyoto Protocol - Annex B) [13]

\begin{tabular}{|l|l|}
\hline REGION & $\begin{array}{l}\text { EMISSIONS TAR- } \\
\text { GETS RELATIVE } \\
\text { TO 1990 LEVELS }\end{array}$ \\
\hline $\begin{array}{l}\text { European Union, Switzerland, most } \\
\text { Central and East European states }\end{array}$ & 8 per cent reduction \\
\hline Canada & 6 per cent reduction \\
\hline United States & 7 per cent reduction \\
\hline Hungary, Japan and Poland & 6 per cent reduction \\
\hline New Zealand, Russia, and Ukraine & stabilise emissions \\
\hline Norway & $\begin{array}{l}\text { increase emissions } \\
\text { by up to 1 per cent }\end{array}$ \\
\hline Australia & 8 per cent increase \\
\hline Iceland & 10 per cent increase \\
\hline
\end{tabular}

Bali Mandate, held at Bali in December 2007 further raises the stakes, and - with it - the hope that there may a turn-around before it is too late. Commenting on the complexity of the negotiation, John Connor wrote in The Age newspaper in Australia on 17 December 2007 under the heading "Ducking and weaving along a risky path to a better future": “After an extraordinary day of global political theatre, about 190 nations hammered out a Bali mandate. The result is a rough and risky road map skirting some dangerous territory, but with some signposts to safety for the future of our planet and our children.” [14].

There is a glimmer of hope. Firstly, there are signs of an awakening and awareness - albeit late - on the part of governments, businesses, major organisations and the international community. There is interaction, collaboration as evidenced by various agreements. Secondly, there seems to be increasing awareness, leading to concerns being vocally and passionately expressed by groups and individuals everywhere! 
The counter measures instituted are yet to produce results. The world at large is eagerly anticipating positive outcomes from these initiatives. Not surprisingly, renewable energy in its different guises is touted as a major element in any of these initiatives.

\section{Renewable Energy}

Many have come to consider the use of renewable energy sources as the panacea for solving the climate change problems. Yet, there is a considerable amount scepticism associated with that.

Renewable energy is variously defined as energy obtained from sources considered inexhaustible. This includes the sun, wind, waves, tides, biofuel and geothermal energy.

In remarkably large instances, the use of renewable energy resources remains as being inextricably linked with generating electricity. That is not surprising in view of the fact that electrical engineering, as a genre, has been the most progressive and influential field of engineering, dominating engineering achievements and providing indispensible means of energy utilisation and communication. So, we need electricity! The popular adage: "no lights without electricity" sums up the reality of being deprived of electricity. Despite its relatively recent debut in the history of humankind, we view having access to electricity almost as our birth right! Our lifestyle has been so entwined with it that we no longer can live without it! It comes as no surprise that access to electricity is no longer considered a luxury, but rather a human right!

Yet, generating electricity using non-renewable sources of energy such as coal and natural gas is one of the major contributors to greenhouse gas emissions. In this instance the right to electricity must be tempered with duty of care. Benign sources of renewable energy need to be found to satisfy both criteria.

In Australia, the concept of renewable energy is linked to electricity by legislation. There is a government instrumentality, labelled Office of the Renewable Energy Regulator (ORER), which administers the legislation and regulations. ORER's aim is to increase the level of Australia's renewable electricity generation. The target set by the newly elected government is $20 \%$ of the total by 2020 [15].

Similar measures are introduced elsewhere.

With reference to the USA, it has been asserted that "renewable energy is a force today and will be a major force in America's future - the only question is when. The answer will depend only on the will of the American people for clean energy - or the next major political disruption in the Middle East.” [16].

That was in 2001. Much water has flown under the bridge since. Collectively, we know better than we did then. The imperatives have become much more compel- ling than we would have believed even just a few years ago [17].

Maybe surprisingly, objections have been raised from different quarters to switching over to renewable energy in an effort to sustain our lifestyle. Objections are usually based on higher costs of renewable energy technologies, including life-cycle costs in the case of solar and wind energy solutions. It has also been pointed out that large quantities of non-renewable resources are required to erect large wind generator towers. It has been argued that most renewable energy installations are aesthetically wanting, whether they be solar panels, tidal power plants or wind turbines. Objections have also been raised to the use of biofuel as source of energy arguing that this would alienate valuable land surface from agriculture and forestry, thus possibly leading to high cost and shortages in basic commodities, most notably food. Such dissenting voices challenge the notion that renewable energy is the panacea in thwarting the gauntlet of climate change.

\section{The Way Forward}

There is unprecedented excitement and activity at all fronts. The UN Organisation seems to have finally spurred on its member states to action. Governments are setting the framework for greenhouse gas reduction, legislating for mandatory reductions in emissions coupled with mandatory targets for renewable energy. Large corporations are investing heavily in renewable energy. All this augurs well!

Also, there is renewed interest in renewable energy education and research. Courses dealing with renewable energy issues seem to be popular in university engineering programs. Research into different aspects of renewable energy application attracts increasing interest. There appears to be a link between consciousness that something must be done and a personal commitment to doing it. It looks as if motivation to engage in renewable energy research is driven by a self preservation instinct as well as communal responsibility. Whichever the reason maybe, interest in research is a good omen.

\section{Role of Education}

Education looms as one of the most important weapons in combating the problems of climate change if it is at all possible to do anything about it. There are many initiatives taken around the globe. These vary from passionately presented programs at elementary levels of schooling to professional engineering degree programs at university level [18] [19].

To place the role of education in the contemporary framework of world events, one has to appreciate the nature of the problems humankind is facing. The problems are universal. They are indiscriminate. They are overwhelming. The humankind is grappling with the almost impossible task of finding solutions to problems beyond its collective comprehension. Parochial interests hamper progress in reaching agreements. Hence, the 
contemporary education has to break through parochial boundaries of national interest, inculcating the importance of selfless cooperation within the global community for common good. Such principles were articulated under Recommendation 96 of the 1972 United Nations Conference on the Human Environment, held in Stockholm, namely: "It is recommended that the SecretaryGeneral, the organizations of the United Nations system, especially the United Nations Educational, Scientific and Cultural Organization, and the other international agencies concerned, should, after consultation and agreement, take the necessary steps to establish an international programme in environmental education, interdisciplinary approach, in school and out of school, encompassing all levels of education and directed towards the general public, in particular the ordinary citizen living in rural and urban areas, youth and adult alike, with a view to educating him as to the simple steps he might take, within his means, to manage and control his environment.” [20].

As the members of the generation which has been slumbering while the climate change has been sneaking on us, we have the onerous responsibility to reach out in educating everyone we can possibly touch. Says Senaka Senanayake - the world renowned Sri Lankan artists, whose paintings adore the United Nations Building in New York and White House in Washington D.C. among many other auspicious places around the world - : "I am quite moved by the environmental crisis and I try to use my skills to attract people to understand and enjoy the beauty of the rain forest. When they become aware they will begin to understand the crisis.” [21]. He focuses on young children, visiting schools, talking to them, showing them his brilliant paintings of the rain forest: plants, flowers, leaves, birds, butterflies. He wants them to see and understand how beautiful the things are that they are about to lose, hoping to arouse passion so that they may become the new guardians of our precious heritage.

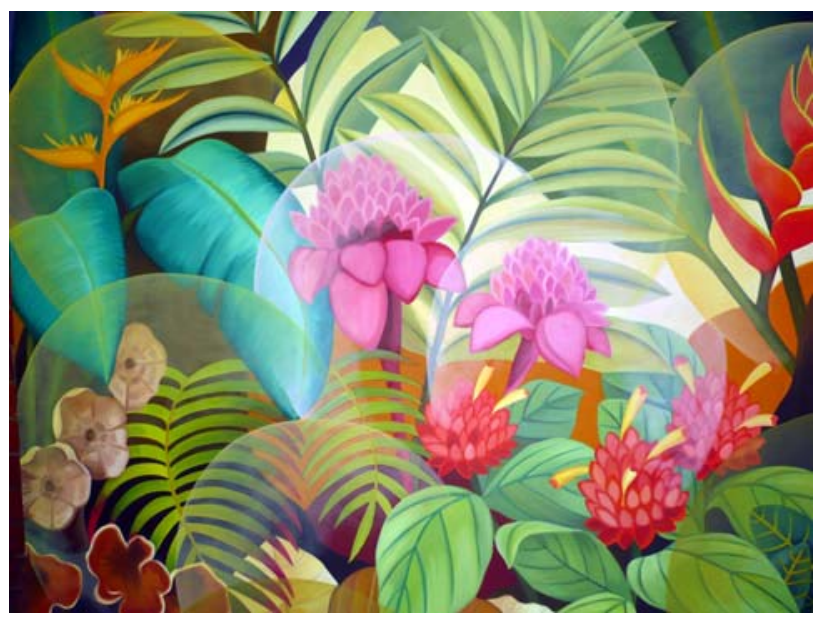

Fig. 1. Splendour of Rainforest as vividly depicted by the world-renowned Sri Lankan artist Senaka Senanayake (Photo Credit: Ö. Göl)

Education is a key ingredient in the fight against global warming and everything else it stands for: education at all levels - from the layman in a country property to the research scholar at a research institution. All need to see how precious the things are that we may be about to lose, and join the fight to save them.

\section{Renewable Energy Education \& Research}

Motivation and passion are sorely needed once one becomes aware of the magnitude of the problems that the humankind is facing. But, motivation and passion are no substitute for skill. Ultimately, sympathetic solutions can only be provided by people who are specifically educated to develop skills to implement renewable energy solutions. This applies in particular to engineering and allied disciplines.

To motivate, to arouse passion for the responsibilities ahead, engineering educators and research supervisors themselves need to be motivated and be passionate about what they are teaching or directing. Following are two examples from opposite sides of the world which may provide some inspiration. Both examples require qualities such as motivation, persistence, dedication, enthusiasm, skill and willingness to learn more skills in a congenial team environment.

\section{A. Solar Decathlon}

Solar Decathlon is a competition, primarily supported the U.S. Department of Energy (DOE), in which teams of university students design, build and demonstrate an attractive solar house of average size [22]. The emphasis is on the sole use of solar energy to provide for all energy needs of the dwelling including electricity, whilst doing it efficiently and attractively. Inaugurated in 2001, it has been held in 2005 and 2007, the fourth event scheduled to be held in 2009. DOE has recently released the names of the 20 teams selected to compete in 2009 Solar Decathlon. The press release also announced that “... each team will receive $\$ 100,000$ from DOE to uniquely design, build and operate an energy efficient, fully solarpowered home for this unique competition.” [23].

The purpose is said to be “... to challenge student competitors ... to think in new ways about energy and how it impacts our everyday lives. To provide those students with a way to show and tell the world what they have learned. To push research and development of energy efficiency and energy production technologies. And to encourage all of us to act responsibly when making energy choices.” [24]. The competition's name - Solar Decathlon - reflects on the ten different contests, by which each entry is judged. They are architecture, engineering, market viability, communications, comfort, appliances, hot water, lighting, energy balance and transportation. Transportation is included as a requirement for providing sufficient electrical energy to charge an electrical commuter vehicle. The teams have some 18 months to analyse, research, design, redesign and build their solar house. Construction is undertaken on the university campus, as depicted in Fig. 2. Once completed and commissioned, the house is dismantled and transported to the National Mall, Washington D.C., for reassembling in a solar village. The reassembled solar house must be fully 
functional before the judging starts. Fig. 3 depicts the extent of functionality: kitchen must provide everything needed to prepare meals the same way it can be done in a conventionally powered home!

Public is invited to come and see the latest-under-thesun! Teams enthusiastically share their knowledge and experiences with the visitors as recorded in Fig. 4.

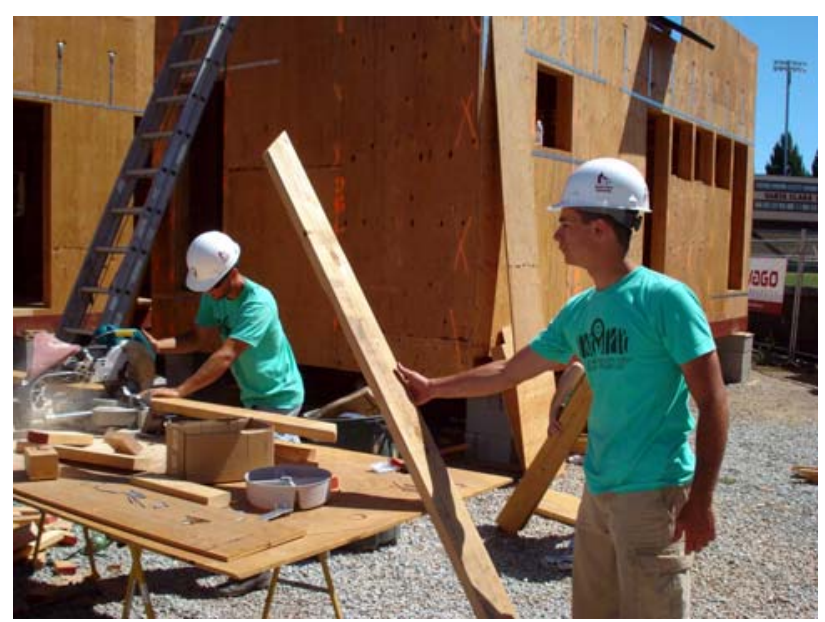

Fig. 2 Santa Clara University assembling their solar house on campus in preparation for $3^{\text {rd }}$ Solar Decathlon

(Photo Credit: Kaye Evans-Lutterodt/Solar Decathlon)

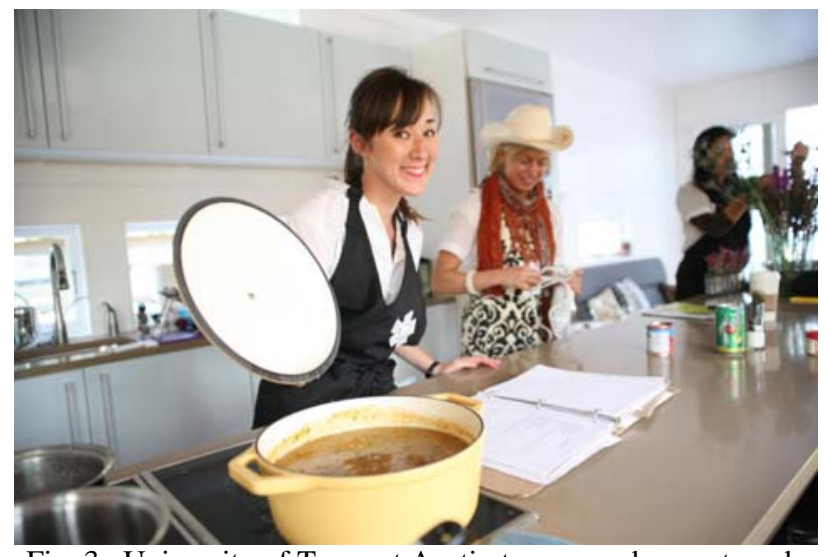

Fig. 3. University of Texas at Austin team members get ready to host solar-village neighbours, demonstrating how effectively kitchen appliances work in their solar house

(Photo Credit: Kaye Evans-Lutterodt/Solar Decathlon)

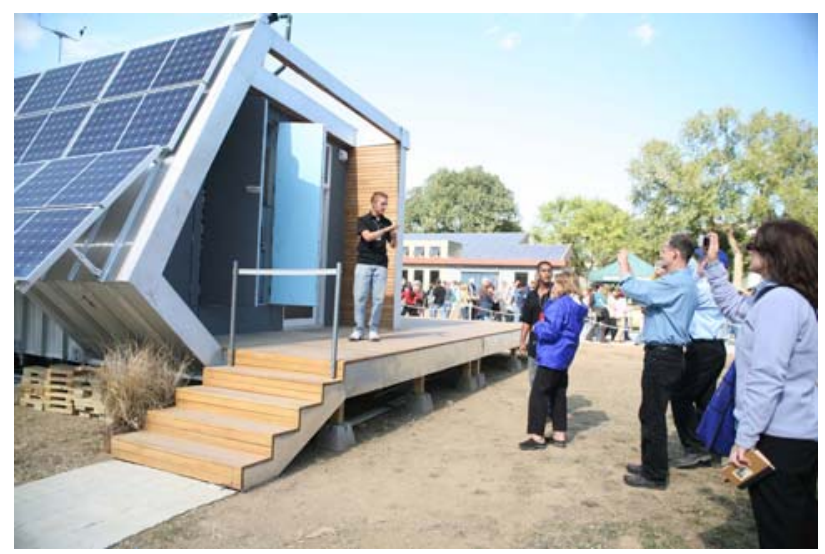

Fig. 4. Kansas State University and University of Kansas "show and tell" about use of structural insulated panels (Photo Credit: Kaye Evans-Lutterodt/Solar Decathlon)
It has been observed that the participants of the Solar Decathlon "... go beyond the requirements of the competition. They get excited about the possibilities and experiment with new ways to build houses" [24]. That's the real power of education which engenders excitement as the basis of motivation!

The Solar Decathlon provides a wonderful contrast to the doom-and-gloom of darkened expectations. It educates. It demonstrates. It offers fresh hope by giving evidence that it can be done.

\section{B. World Solar Challenge}

World Solar Challenge is a race across the continent of Australia from Darwin in the north to Adelaide in the south, covering a distance of just over $3000 \mathrm{~km}$ [25]. Its purpose is to promote research into zero emission transport solutions. As the name implies, solar energy is the sole source of energy for use during the race.

In 1997, the South Australian Solar Car Consortium was formed upon the initiative of the University of South Australia (UniSA). The consortium included UniSA and three local high schools. The aim of the Consortium was to motivate students to take up engineering as their study path upon completing high school, in addition to raising their level of awareness of environmental issues. This was to be achieved by helping design and build a real solar car for real people to participate in a real race. The real race aimed for was to be the World Solar Challenge (Fig. 5)! The first solar car, nicknamed "Ned" after Australia's most infamous folk hero Ned Kelly, was designed and built under the enthusiastic and capable supervision of academics, who infused their enthusiasm in the students working as composite teams (Fig. 6). These comprised university students from various engineering disciplines and high school pupils. Ned made its debut at the 1999 World Solar Challenge, coming first in its class and 14th overall.

In 2000, Regency TAFE, a college of technical and further education joined the consortium. Soon, the Consortium was working on Kelly, the next generation solar car.

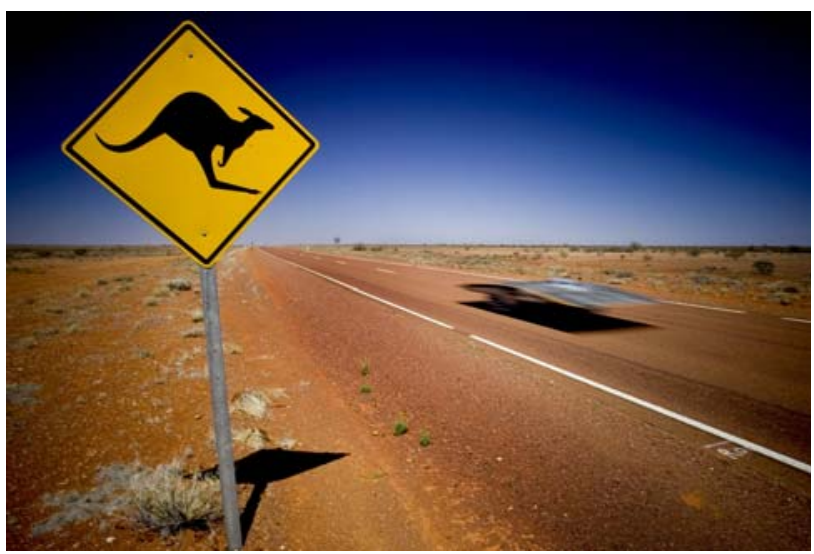

Fig. 5. Route from Darwin to Adelaide in World Solar Challenge solar car race

(Photo Credit: Events South Australia/World Solar Challenge) 


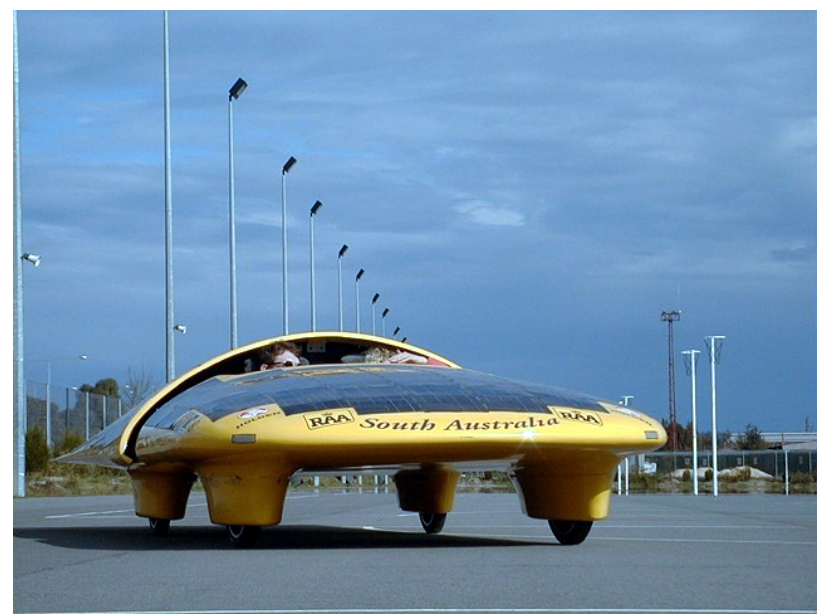

Fig. 6. Solar car designed and built by the South Australian Solar Car Consortium

(Photo Credit: UniSA/World Solar Challenge)

Meanwhile, UniSA team had accepted the challenge of designing and building an ultra-efficient, low-mass electric vehicle powered entirely by renewable energy. Thus, work started on Trev: Two-seater renewable energy vehicle (Fig. 7).

Two-seater, because most trips in metropolis have one or two persons only in a vehicle! Trev's features have included sufficient room for modest luggage, energy efficient tyres, brakes and suspension, a quiet and efficient electrical drive, and - of course - compliance with road safety regulations and road worthiness requirements. Trev weighs $300 \mathrm{~kg}$ and has a driving range of $150 \mathrm{~km}$ before it must be recharged. Its energy consumption is about $20 \%$ of a comparable passenger vehicle.

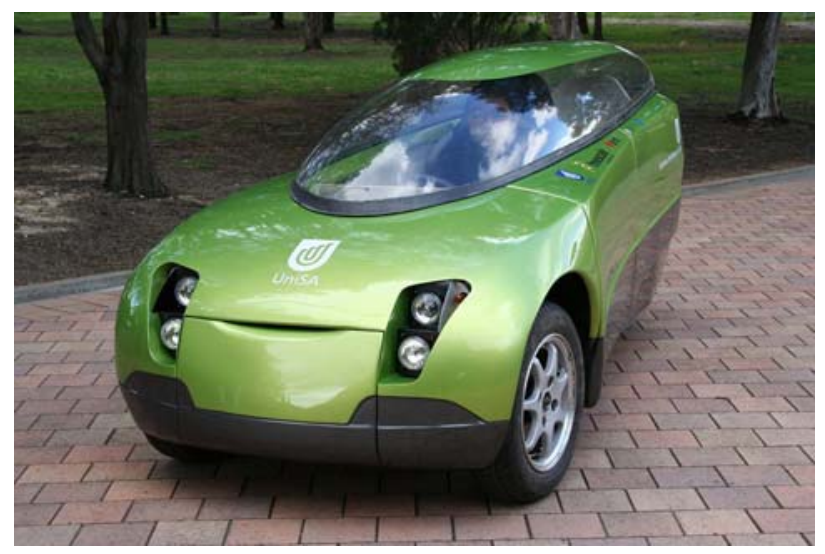

Fig. 7. Two-seater renewable energy vehicle: Trev, designed and built at the University of South Australia (Photo Credit: UniSA/World Solar Challenge)

It can accelerate from standstill to $100 \mathrm{~km} / \mathrm{h}$ in less than 10 seconds, doing so smoothly and quietly. The tandem seating arrangement results in good stability and visibility. The single rear drive wheel simplifies the suspension, and allows a simple, efficient transmission. It has an aerodynamically designed and aesthetically pleasing body with a transparent canopy. Both the canopy and the door open on the kerbside for safe access.
Trev was successfully entered in the 2007 World SolarChallenge in the Greenfleet Technology Class. It completed the race in just over 6 days. Energy consumption was $6.2 \mathrm{kWh} / 100 \mathrm{~km}$ [26].

\section{Conclusion}

It is now beyond question whether the planet Earth is threatened as a habitat for life. The overwhelming evidence points to the possibility of our planet becoming unfit to sustain life.

There are compelling reasons for humankind to embrace any measure which offers a glimmer of hope to deviate from the perilous course that we are on without having counted the cost in the first place. Young generations offer much promise in achieving success to stem the flow toward the seemingly inevitable.

Engineers carry a special responsibility on account of their knowledge and skills in dealing with issues arising from the conversion and use of energy. This behoves us to take a lead and be actively involved in matters pertaining to climate change and renewable energy.

Is it too late? Some say it is! The hope is that we will somehow sail out of troubled waters provided we pull together.

\section{References}

[1] W. Paddock, P. Paddock, Famine-1975! America's Decision: Who will survive?, Little, Brown and Co., Boston (1967), $286 \mathrm{pp}$.

[2] P. R. Ehrlich, The Population Bomb, Ballantine Books, London (1968), 223 pp.

[3] N. Eberstadt, (1995), "Limits of Statistical Certainty: The Case of Population, Food, and Income", in The True State of the Planet, (R. Bailey, ed.), Free Press, New York (1995), pp. 455-459.

[4] IPCC, 2007: Climate Change 2007: The Physical Science Basis. Contribution of Working Group I to the Fourth Assessment, Report of the Intergovernmental Panel on Climate Change [Solomon, S., D. Qin, M. Manning, Z. Chen, M. Marquis, K.B. Averyt, M. Tignor and H.L. Miller (eds.)]. Cambridge University Press, Cambridge, United Kingdom and New York, NY, USA, 996 pp.

[5] United Nations Conference on the Human Environment, 1972, Stockholm, Sweden, http://www.unep. org/Documents.Multilingual/Default.asp?DocumentI $\mathrm{D}=97 \&$ ArticleID=1503\&l=en (last viewed 5 February 2008).

[6] United Nations Conference on the Human Environment, 1972, Stockholm, Sweden, http://www. unep.org/Documents.Multilingual/Default.asp?Docu mentID=97\&ArticleID=1515\&l=en (last viewed 5 February 2008).

[7] United Nations Conference on Environment and Development (UNCED), Rio de Janeiro, 3-14 June 1992, http://www.un.org/geninfo/bp/enviro.html (last viewed 5 February 2008). 
[8] Johannesburg Declaration on Sustainable Development, http://www.un.org/esa/sustdev/documents/ WSSD_POI_PD/English/POI_PD.htm (last viewed 9 February 2008).

[9] Australian Government Bureau of Meteorology, “Annual Australian Climate Statement 2005”, http://www.bom.gov.au/announcements/media_relea ses/climate/change/20060104.shtml (last viewed 2 February 2008).

[10]Ecologic - Institute for International and European Environmental Policy, http://www.ecologic.eu/mod ules.php?name $=$ News \&file $=$ article $\&$ sid $=2238$ (last viewed 30 January 2008).

[11]R. Pachauri, "Presentation at the Opening Session of the UN High Level Event on Climate Change, New York, 24 September 2007”, http://www.ipcc.ch/grap hics/speeches/rajendra-pachauri-september-2007.pdf

[12] Z. Yu, Issues on Renewable Energy Development in China, Power Engineering Society General Meeting, 2007, IEEE, DOI 10.1109/PES.2007.386158, pp. 16.

[13] Kyoto Protocol to the United Nations Framework Convention on Climate Change, http://unfccc.int/ resource/docs/convkp/kpeng.html (last viewed on 1 February 2008).

[14] J. Connor, "Ducking and weaving along a risky path to a better future”, http://www.theage.com.au/ news/climate-watch/ducking-and-weaving-along-arisky-path-to-a-better-future/2007/12/16/119774009 0794.html (last viewed 5 February 2008).

[15] Australian Government - Office of the Renewable Energy Regulator, “Increasing Australia's renewable electricity generation”, http://www.orer.gov.au/legis lation/index.html (last viewed 5 February 2008).

[16] S. R. Bull, Renewable Energy Today and Tomorrow, Proceedings of the IEEE, Vol. 89, No. 8, August
2001, pp. 1216-1226.

[17] K. Malmedal,B. Kroposki, P. K. Sen,Energy Policy Act of 2005 and Its Impact on Renewable Energy Applications in USA, Power Engineering Society General Meeting, 2007, IEEE, DOI 10.1109/PES.2007.386060, pp. 1-8.

[18]R. B. Bass, A Bachelors Degree Program in Renewable Energy Engineering, in Proceedings Frontiers in Education Conference, $36^{\text {th }}$ Annual, 27-31 October 2006, pp. 13-16.

[19] B. Hadzi-Kostova, Z. A. Styczynski, Teaching renewable energy using multimedia, in Proceedings Power Systems Conference, 10-13 October 2004, vol. 2, pp. 843-847.

[20] United Nations Conference on the Human Environment, 1972, Stockholm, Sweden, http://www.unep. org/Documents.Multilingual/Default.asp?DocumentI $\mathrm{D}=97$ \&ArticleID=1511\&l=en (last viewed 5 February 2008).

[21]H. Bhatkal, Senaka, Popular Prakashan, New Delhi (2008), p. 175.

[22]U.S. Department of Energy, Solar Decathlon, http://www.solardecathlon.org/ (last viewed 1 February 2008).

[23] U.S. Department of Energy, “Energy Department Selects Student Teams to Compete in 2009 Solar Decathlon”, http://www.energy.gov/news/5888.htm (last viewed 28 January 2008).

[24] U.S. Department of Energy, "Solar Decathlon: Fulfilling a Purpose”, http://www.solardecathlon.org/ purpose.html (last viewed 28 January 2008).

[25] World Solar Challenge, http://www.wsc.org.au/ (last viewed 1 February 2008).

[26] University of South Australia, Trev (two-seater renewable energy vehicle), http://www.unisa.edu.au/ solarcar/trev/ (last viewed 28 January 2008). 